\title{
Reconversion of Flat Buildings Administration: New Romanian Business Opportunities
}

\author{
Nagy Zsolt ${ }^{1, a}$, Fülöp Ludovic ${ }^{2, b}$ and Talja Asko ${ }^{2, c}$ \\ ${ }^{1}$ Baritiu 25, Cluj-Napoca, Romania \\ ${ }^{2}$ Kemistintie 3, Espoo, Finland \\ a zsolt.nagy@dst.utcluj.ro (corresponding author), ${ }^{\mathrm{b}}$ ludovic.fulop@vtt.fi, ${ }^{\mathrm{c}}$ asko.talja@vtt.fi
}

\begin{abstract}
Keywords: flat building administration, business models, ownership models, maintenance practice, renovation solutions.
\end{abstract}

\begin{abstract}
In Romania, after the changes in 1989, most flats in existing buildings were sold to the occupants. This was a sort of "getting back" for those people who lost their private property, but another reason of this decision was the missing centralized management capacity of the administration. Looking back now and analyzing from the point of view of how property was redefined at that time, we can say with no doubts: it was made in a wrong way, and as time passes this will become a disaster. Tremendous progress was made in the last twenty years in any areas of life, but the existing stock of flat buildings still regresses from all points of view. The pushed administration model for new flat buildings also produces similar negative effects. The reason can be found on one hand in the way how private property division was done. On the other hand the so called "owner administration" model in most of the cases cannot work efficiently due to lack of knowledge, division, overemphasizing individual interest etc. This paper makes an up to date analysis of present Romanian situation and define new business opportunities, supplying business models for existing and new flat building administration. Applying a reconversion process, positive economical effects and improvement of the comfort and life quality of the owners of such kind of private properties could be achieved.
\end{abstract}

\section{Introduction}

\section{General Overview.}

The Soviet Union was the first country to develop prefabricated panel buildings programs (1920s-1930s) aimed to build new dwellings for the population that came from the countryside to work in factories. In other East European countries the large panel-house building programs started somewhat later: 1965 Hungary [0], 1956-58 in Czechoslovakia, and 1958-1960 in Romania. By the end of the 1970's prefabricated concrete panel buildings became the dominant form of construction.

The political administration adopted quickly the prefabricated building system, as it proved to be quick and cheap to erect. Of course, the social dimensions of forced mass migration of workers are also very important. As the key objective was to strengthen the economy, the industry developed with a high annual rate and therefore more and more man power was needed in the urban areas. The need of new dwellings increased significantly and a massive construction program started, using state funding.

\section{Panel buildings in Romania.}

In Romania, most of the currently occupied 57431 prefabricated panel buildings have been built between 1960 and 1990. The overwhelming majority, 41540 buildings have 5 floors. A second group of important typologies are the 9, 10 and 11 floors totalling 9180 buildings. All other configurations total only 7440 buildings, 300 taller than 11 floors, 4920 buildings lower than 5 floors and 2220 buildings having 6,7 or 8 floors. Practically the two most widespread configurations in Romania are the 5 floors and the tower $(9,10,11$ floors) typologies, with very few other configurations (Fig. 1). 


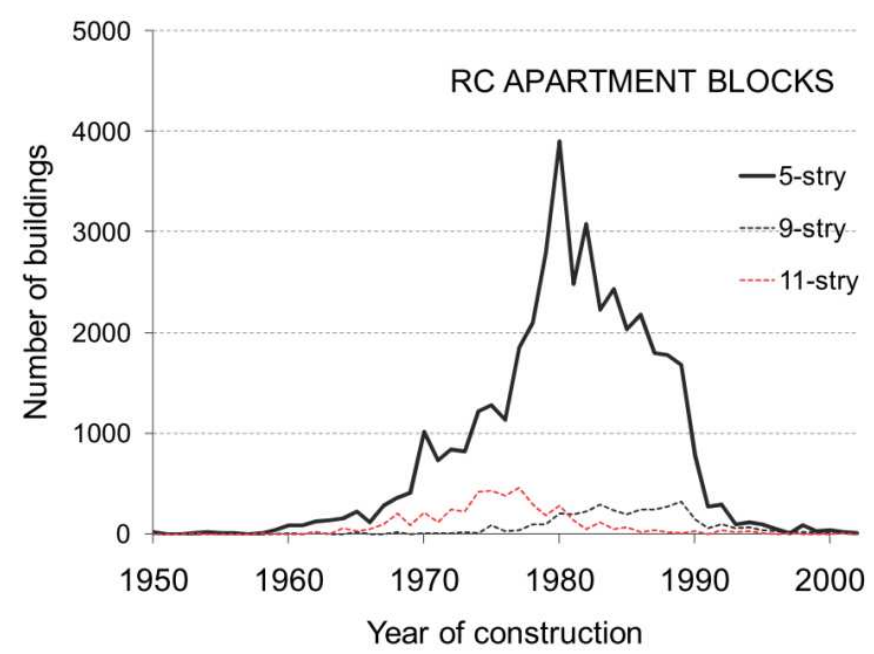

Figure 1. Number of buildings each year (I. Demeter [0]).

One disadvantage of the buildings erected before the ' $60 \mathrm{~s}$ is that there were no seismic design codes. In 1963 the first seismic design codes were adopted. Therefore panel buildings built after ' 60 s had some improvements regarding the structural design and the functionality of the apartments. The panel buildings built after 1964 have the concrete class B200 (C12/15) whereas the ones build before only B150. An important milestone in the panel building program in Romania has been the Vrancea earthquake in 1977, which motivated the authorities to implement several changes in the building configurations in order to increase earthquake safety. E.g. the 11 stories tower configuration, most commonly used in the decade 70, has been replaced by the 9 stories configuration for the 1980's [0]. But the 5 storey configurations have been affected only at the level of detailing connections between panels, and the quality requirement for materials.

Actual housing situation. Comfortable housing in a safe environment is a fundamental necessity, which is still a challenge for many European countries. According to Eurostat [0], in $2009,41.8 \%$ of the European population lived in flats, a significant part of which are panel buildings, especially in East Europe.

According to the Census of Population and Housing of 2011, Romania had 19.0 million inhabitants. They were living in 8.5 million dwellings with 22.7 million rooms, on a total living area of 398 million $\mathrm{m}^{2}$. The average dwelling has 2.7 rooms and 2.66 inhabitants. $52.8 \%$ of the population is urban - most of the flat buildings are concentrated in the urban areas. The number of flat buildings is 84000 , with 2.5 million apartments.

Home ownership rate is very high, and buying with credit is not common or desired choice. Only the young generation is open to enter credit schemes - and following the lessons of the economic crisis of 2008-2009, reluctance was strengthened.

At the market psychographic level, there are some general characteristics to be mentioned:

- "Home" is a priority for people, but "Home" is ending at the apartment door (worst case), or at the entrance to the building;

- Therefore, public area is out of focus and often looks neglected;

- Global view of facade neglected;

- Lot of things to do for improvement.

\section{Flat Buildings Characteristics: review of technologies.}

The fundamental outcome of this building technology is a system of boxes with a standardized layout depending on the size of the panels (Fig. 2).

The basic element of the prefabricated blocks is the wall panel, a plate element forming a wall or a floor/roof of a room. If the panel is exterior, it is made of three layers of material, 2 concrete layers for load bearing and protection against weather, and one thermal insulation layer in between which is usually mineral wool. 
The panel connection - horizontal and vertical are the key structural component of a panel building. Depending on the construction technology, they can be wet (with cast-in place concrete poured between the concrete panels) or dry (realized by bolting together steel plates cast into the ends of the panels).

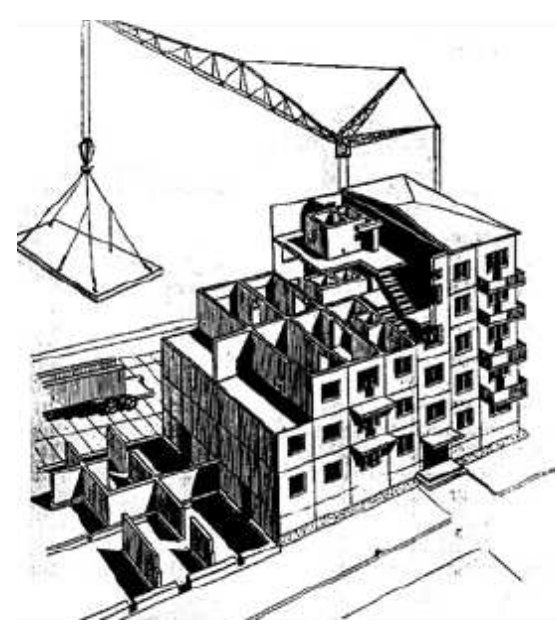

Figure 2. A large-panel concrete building under construction. [5]

The large-panel flat buildings erected decades ago were not built to have a certain life period, as the codes of that time did not have such specifications. Nevertheless, their intended life period was approximately 50 years. The majority of them did not undergo major maintenance operations as they were not in a monitored maintenance program which should have been established at their erection.

As a result of the initial low quality of built, cumulated with inadequate maintenance practices and social problems associated with the forced creation of new communities the panel neighborhoods, lead to a generally negative perception.

Flat buildings in Romania, built more than 50 years ago, have the following major problems:

- They need structural repair and consolidation operations;

- Most of the flat buildings erected before 1990 need thermal rehabilitation - they are in low energetic classes, and the heating costs are very high [6] ;

- The plumbing is old;

- The electrical system is outdated;

- The Homeowners Associations (HOA's) do not have the necessary resources to successfully solve the problems that arise.

Ownership Models in Romania and Central European Countries. The apartments built 1950-1990's were owned by the state. The inhabitants were tenants that in the majority of cases moved from the countryside to work in the factories. Due to the political ideologies of the regime, the private property technically disappeared.

This situation changed after 1990, when the private property became protected and guaranteed by law. The authorities decided to sell the apartments to the tenants, initially at the price of 100.000 lei (the average price from 1989 - approximately 4500 euro), equivalent to 32 monthly salaries. As the inflation was out of control, in 1993 this sum represented only 1-2 monthly salaries. The price of the apartments, though, did no change. Therefore, one apartment could be bought with only a few hundreds of Euros. As a result, in Romania around $96 \%$ of the apartments are owner occupied.

Anyhow, in other countries the authorities treated the concept of private property differently. In Germany there are still a large number of apartments owned by state-run housing companies or cooperatives. They regularly maintain the grounds, as the German laws require the flat owners to invest in their housing stock or otherwise lose their apartments.

Condominium versus collective ownership. The ownership model, implemented in Romania after privatizing the state owned apartments is that of condominium type ownership. In this scheme, the apartment itself is private property, while shared parts of the building are used under legal right 
associated with the owning of the apparent. They are divided co-property of the apartment owners; co-owned by them. Co-ownership, "coproporietate" in Romanian legal terminology, extends to all commonly used parts of apartment buildings, land, foundations, cellars, stairways, elevators, external walls, roofs, depositing areas, entrances etc. Owners are organized in home owner associations or HOA's, for the purpose of managing the co-owned parts of the property, but also to pay utility bills and other costs that are not divided by service providers to individual owner level.

The law states that local authorities have to support the HOAs. However, in their current form, HOAs lack managerial skills and professional expertise for management, economic or legal issues.

An alternative model for owning buildings (not specific for Romania) is the so called collective ownership model. This is the most frequent ownership model in Nordic Countries. In such houses, the right to reside in a particular house or flat is tied to the ownership of shares in the housing company. In essence, the housing cooperative owns the building/buildings, and the shareholders own the housing company. The ownership of shares associated with an apartment automatically entitles one to live in that apartment.

In practice all owner-occupied residential apartments in blocks of flats are managed by housing companies in Finland. The main advantage of the scheme is that the housing company, as legal entity, is able to enter agreements for maintenance and renovation, or to sign loan agreements with banks for the financing of such renovation. Residents pay a monthly fee to the housing company to cover maintenance costs, loan costs, heating costs and the water supply. Housing company decisions are defined by residents at open meetings.

Influence of Ownership Models on Maintenance Practices. Despite the many shortcomings of the panel building typology and their negative perception, their replacement is not a viable option even on the medium to long term. Hence, viable maintenance and upgrading solutions have to be found and promoted. Below a list of problems is presented with the aim of searching solutions.

One difficulty in HOA, as organized in Romania, is the lack of ability to agree on maintenance and renovation. Traditionally, it takes the full agreement of all owners to contact a bank loan to finance renovation of the building. As noted by Egedy [0] in a case of an association of 100 owners there is practically no chance to achieve such unanimity, throwing the HOA in impossibility of taking a decision.

This has been the general situation also in Romania, until recently. But even with the lowering of the required votes from $100 \%$ to majority, will make the group to decide to renovate, and then force a private individual to pay a bill. This approach has its limits, as the person might not be in the situation to pay or guaranty a loan individually. So the leverage of the group over the individual is limited. No surprise that current financing schemes for renovation leave only a minor part of the expenses to be paid by owners. E.g. $20 \%$ in Romania is paid by the owner while $50 \%$ and $30 \%$ by the state and the local authority. But $2 / 3$ of the loan interest financing the renovation was paid by the state in the panel renovation program launched in 1995 in Hungary too [0].

In the collective ownership scheme, the situation is different. Once the decision is taken by the owners meeting, the contracting of the bank loan is not an individual burden, but it is done by the housing company. The guaranty to the bank is the collectively owned building, and the individual shareholder pays the interest corresponding to his shares in the housing company; or pays off his share of the housing company loans. Apartments, more precisely shares, are freely sold on the market with outstanding renovation loans; the loans are simply transferred to the new shareholder and they can be used as collateral for a bank loan.

In the collective ownership scheme, the housing companies use usually external housing service, whose main task is to manage the property in accordance with the housing company's decisions. Also the building site is treated because the housing company either owns the land or has leased it from the city by a long-term contract.

There are numerous cases presented by the media highlighting the inefficiency of the HOAs management system in Romania [7], [8], [9]. One of the main flaws is that management tasks are carried out by untrained administration staff. The president, censor and administrator are eager to 
hold their position even when they have no ability to promote good management, or maintenance and repair practices. As result of widespread amateurism, many HOAs were penalized by the city as they proved to have been writing unreal amounts of expenses on payment lists.

As summary, at the market psychographic level one can observe the attitude, that:

- "Home" is a priority for people, but "Home" is ending at the apartment door (worst case), or at the entrance to the building;

- Therefore, public area is out of focus and often looks neglected ("Not mine!");

- Global view of facade neglected ("Not mine!”).

\section{Steps Forward: Reconversion - New Models for Building Administration}

Many of the difficulties of the Ministry of Regional Development and Tourism (MDRT) managed national program of renovation and increasing energy efficiency can be traced back to the structure of ownership.

The MDRT program is paying a substantial share of the cost of renovation, and also demands the HOA's to work together as a whole - not accepting exceptions on the side of the owners. Still the program is missing to address the complex problematic related to panel building neighborhoods, being exclusively focused on thermal rehabilitation, i.e. putting external thermal insulation and changing the windows. Even in this respect, there need of more systematic approach, if the improving of the aesthetics of the buildings is desired.[10]

It is also a disadvantage, that immediate costs are virtually the only drivers of choice of renovation solutions. Not using life cycle costing and not being more safety conscientious leaves HOA's to choose a cheaper and fast solution.

Four business strategies were identified to reconvert the building administration and activate the retrofit market in Romania. The models are based on a different ownerships and practices in Romania and the Nordic countries. Due to space limit, we discuss the visions as potential possibilities and analyse their weaknesses and strength for only three. The four strategies are:

1. ReNova LTD (Franchise System) - with renovation services as a product. The target is the developer, construction company, managing companies (MC's);

2. RetroCon (Profit-hunter facilitator Company) - creating an association of companies to offer refurbishment services;

3. ARetro (Assisted self-organizing model) - facilitate HOA's own organizing. MC's created by direct private investment. Support creation of MC's from markets with experience to transfer know-how transfer;

4. Coordinated Change - Pushing by regulation model. Energy auditors promote solutions, know-how exchange with energy auditors. (Not detailed in this paper).

\section{Franchise System}

ReNova LTD, is large corporation primarily interested in selling renovation solutions to the construction market. ReNova executes a plan to partner with local companies in order to distribute its innovative, "turnkey" solutions for retrofitting and improving energy efficiency existing building stocks in emerging markets.

The keys to success:

- Creating an effective and trusted support/selling base with local construction and development companies;

- Support with technological know-how the network, both at the bidding and execution phase;

- Respect the interest of the local "dealer networks" and their ability to market the product to their customers; Cautiousness with partners in the network - today partners may turn out tomorrow's competitors. Be one step ahead in innovation - always have a new upcoming product. 
Mission. The mission of ReNova is to bring technological know-how to the EEC market, providing technological support to local development and construction companies. Dealing with the end users, the HOA's, is left for local market players. Providing services to, and supporting the local companies in identifying market needs and viable service and product ranges for the future is the key feedback loop needed to keep ReNova in competition.

For short term: To start and steadily expand the dealer's network, starting with key local players in the renovation business

For long term: Constantly create new ways to facilitate the work of the network by technical supporting, evaluation software, studies supporting the marketing of products and services. Keeping the network connected to ReNova by periodically launching innovative products.

The objectives are to start and expand the dealer's network, to collect feedback from dealer network and to improve support services - these are directed to dealer network (construction companies and developers), not end user's e.g. HOA's.

Planned service package.

- Technology - The product range of ReNova will be sold to the network together with technological know-how, planning and design support and training for development and construction companies. ReNova gradually develops the online support system for the companies in the network.

- Collaboration within network - On the feed-back loop ReNova collects information from companies concerning the opportunity of introducing new product ranges to market, or to develop entirely new product ranges based on market demand.

- Promotion of sustainable retrofitting - ReNova will launch and develop online site and planning support tools directed to HOA's and building owners. The aim is to educate the end user concerning aspects of sustainability and eco-efficiency of the renovation choices. Another aim is to provide very basic tool to support decision by end users in favor of ReNova products.

Market Analysis Summary. The main customer focus of ReNova is on local emerging construction companies carrying out renovation work. Most of these companies are of small, and they need support in the learning phase of adapting ReNova technology. What they contribute to the partnership is their local clientele, where they start promoting ReNova solutions instantly. Choosing dynamic companies for the network is essential.

ReNova will take decision on tolerating the use by the partner companies of other/competitor's solutions in parallel with ReNova's on the case-by-case basis. As the ReNova brand is becoming more established on the market, stricter criteria can be applied.

Developer companies are the secondary focus of ReNova. They are less active in the renovation business, and usually have their own networks of designers/builders.

\section{Profit-hunter facilitator company}

RetroCon, is an organization created to execute this plan - in order to supports real estate development companies and House Owner Associations (HOA's) in their management of changing to a sustainable model for their building stock. This support includes the management of new technological discoveries, carrying out thermal retrofitting of old buildings and improving the usage of energy, transforming inefficient buildings into sustainable ones, making in that way a step forward in thinking green and improving the quality of life of the occupants.

The keys to success:

- Building a strong support base with real estate development companies and HOA's;

- Creating an effective network between MC's and HOA's to facilitate crosscommunication;

- Raising the viability of know-how and technology transfer from established markets;

- Strong and straight forward communication with HOA's to facilitate the change. 
Mission. The mission of RetroCon is to bring know-how, technologies and applicable business models to Eastern European countries into public use; thereby providing development assistance to real estate development companies and HOA's to improve the efficiency of energy usage, providing service to the technology transfer staff of each institution by assisting in identifying, protecting, developing and transferring technology to the private sector and generating income. RetroCon perspective is in its ability to link market players from various private companies to transfer knowhow that can then be marketed in the private sector.

For short term: To start retrofitting buildings, which first service time was long time ago elapsed;

For long term: Redefine the objectives and status of HOA's, developing long-term relationships with the new defined Administrative Business community.

The objectives are the followings:

- Increase of corporate membership in RetroCon;

- Establish the contact with the Owner Associations Federation from Romania (FAPR) [11], and other active organization;

- Achieve an increase of membership by $15 \%$ each year;

- Create new linkages between industrial partners and developers and develop new collaborative relationships between main players;

- Develop a RetroCon webpage / database that will link players in this project.

Planned service package.

- Technology - Assist in identifying potential application of developed solutions and evaluation of these application areas to determine the commercial potential. A database should be created and maintained by RetroCon in order to respond quickly to requests for information from HOA's and developers. It should be created a quick and accessible resource that will identify applications and industrial partners that match their interest areas;

- Industry Collaborations - RetroCon will actively seek collaboration opportunities between industrial partners and HOA's / developers;

- Retrofitting Technology Conferences - RetroCon will organize two conferences in Romania each year, focusing on the areas of Energy Efficiency, Sustainability and Retrofitting Technology;

- Newsletter and Promotional Publications of old building retrofitting - RetroCon will produce a quarterly promotional publications directed toward the home owner association which will focus on current development / case studies on retrofitting.

Market Analysis Summary. RetroCon will first focus on creating the information base necessary to satisfy industrial players that are currently prospecting for applying the existing retrofitting technologies. Branded companies are an advantage, but also include medium-to smallsized companies.

Two important groups of potential targeted customers were identified: development companies and HOA's. Both of them have limited resources and know-how to manage the owned building. It is critical that they find RetroCon an excellent tool in quickly identifying retrofitting technologies and know-how that will lead them to achieve their new goals.

RetroCon will provide a service that will correspond to the agreed set up in the consortium council. There will be both a full and associate membership option in the Retrofit Technology Consortium Council. Larger companies will select the full membership option because it will offer additional research services. An associate membership is tailored for the medium- to small-sized companies whose contacts will be less frequent.

Market Segmentation. For larger companies it is critical to create major stakeholders in the development of a better delivery system for technology transfer. Currently, there are several large companies that have an on-going business relationship in Eastern European countries. Recruiting these companies as full members of the Retrofit Technology Consortium Council is an important first step in improving corporate interest in targeted countries. These companies will be responsive to RetroCon ability to develop the retrofit business in those EEC that they are interested in 
development. RetroCon will also facilitate the infrastructure that will lead to the pursuit of EEC that these companies are interested in. Involvement in the growth of RetroCon will attract companies of similar size and stature.

Medium to Small Companies: these companies are critical to the growth of RetroCon because they are flexible and could cover those areas in which larger companies are not interested. Their focus in not only on a specific technology that is being developed in the RESPIRE project [12], but also on particular project for which they are able to develop their own particular solutions. As associate members of the Retrofit Technology Consortium Council, these companies will gain opportunities that will meet their technology and staff needs.

\section{Assisted self-organizing model}

ARetro is an association supported by the construction companies active on the renovation market, producers of renovation products and local authorities - with the scope of education Home-Owners Associations (HOA's) about benefits of sustainable renovation. The activity of ARetro includes a strong online presence, the organizing of community meetings for the public and/or with HOA's administrators, and providing legal advisory for starting renovation projects.

ARetro also promotes networking of HOA's - in the HOA Adoption scheme and experienced HOA is guiding a beginner in starting a renovation. ARetro's focus is benefiting society, companies/authorities can only benefit indirectly by the increasing of the retrofit activities.

Keys to success:

- Picking-up the most important barriers HOA's face when starting retrofitting - strong communication with HOa's;

- Providing up-to date legal information;

- Having a useful, practical, simple and always updated online presence;

- Publicising the success stories of HOA's after successful completion of renovations.

Mission. The mission of ARetro is to educate people about the benefits of sustainable retrofitting. About the potential benefits; how such retrofit can improve their living standard, result in energy savings, benefit the environment etc. Another focus of ARetro is to provide free and reliable information about the technical and legal aspects of starting and successfully concluding a renovation project.

By these measures ARetro is encouraging HOA's and owners to become customers of retrofit solutions.

For short term: to become the most trusted online provider of information concerning legal and technological aspects of retrofitting - a reference site to HOA managers.

For medium term: to develop an online toolset (document templates, calculation sheets, model contracts etc.) to support HOA's in increasing the efficiency of their activity

For long term: help HOA's to re-focus them from short-term administrators to long term planners and responsible for maintaining the properties in their administration

The objectives are the following:

- Attract an online readership of 10000 hits/week, and 500 registered HOA's as free members;

- Organize monthly seminar to HOA administrators in all major cities of target counties have an increase of $10 \%$ yearly in number of seminars delivered;

- Facilitate 20 HOA Adoptions every year in the first 3 years.

Planned service package.

- Technology - In terms of technology ARetro is only a distribution platform of technical information from producers to end users. Articles about good practice examples are also hosted on the site; 
- Industry collaboration - On the medium term part of ARetro financing is coming from industry sponsorships. In return ARetro hosts promotional material from industry partners, publicizes good practice examples and uses material from industry in its seminars;

- Collaboration with public authorities - ARetro seeks close collaboration with authorities - the benefits ARetro gives to local community are (i) preservation of value of the building stock because of sustainable renovations practices and (ii) creation of employment opportunities to local small companies. ARetro seeks to quantify these benefits when informing local authorities;

- Public presence - Presence in local media is very important in order to attracts HOA's ARetro seeks to be feature at least monthly in local newspapers.

Marketing and funding strategy. It is critical to initiate the site with an appealing content. In next step ARetro will publicise the upcoming seminars in local newspapers and fliers, to attract interested parties. ARetro will also seek support of the local authorities of towns where seminars are held. Building the networks with HOA's will be based on direct contacts within the seminars. Once a critical media attention is reached, and the network of HOA's is sufficiently extended, ARetro starts marketing its activity to local construction companies first gradually reaching out for larger material producers.

Milestones. ARetro 's milestones are as follows:

1. Within 2 months from initiation of the Start-up public project, have a functional site on the net;

2. Within 4 months reach the 1000 hits / week, and have the first seminar held;

3. Within 6 months have at least 50 HOA's registered users;

4. Within one year have company sponsorship contract representing $10 \%$ of operating cost;

5. Increase by $10 \%$ of operating cost company sponsorship every month for next 6 months.

\section{Conclusions}

Based on the review of the Romanian market situation reported here, and the discussions, the following general conclusions can be drawn:

- A great and growing need exist for renovation of the concrete panel building stock in Romania. Most of the buildings are built in the 70's and 80's and they are reaching the service life stage when retrofit is unavoidable. In this respect, only small stimulation can create good results on the market;

- Renovation market is quite new and rapidly evolving - competition is not yet fierce, but international companies are attracted by increasing number of EU and Government financing programs;

- Financing programs have particular rules; they are often overly bureaucratic and are sometimes distrusted by the beneficiaries/end-users - the Home Owner Associations;

- Home Owner Associations have no technical and legal knowledge to navigate the renovation process. It is imperative to support the HOA's with technical and legal information (private sector, associations, local authorities). Lack of good technical information already results in substandard ad-hoc renovation solutions being applied with no responsibility;

- Existing weak legislation and lack of information on the side of HOA's is already creating disastrous renovation examples in Romania;

- We sketched 3 possible business models for private actors operating on the renovation market or interesting in accessing the market. Because the models were not tailored to a certain market player they are sketchy. They also represent different depths of involvement in developing the market - but in all cases important emphasis was put on 
educating/informing/strengthening the HOA's, because the authors felt that they do represent a weak link in implementing a sustainable future focused retrofit strategy for the panel building stock.

So, reconversion will bring a more comfortable life? Not easy to answer. But, certainly, one fundamental problem of administering panel buildings is related to HOA's inability to take decisions as an entity; individual interest overriding/blocking the interest of the group. Authorities should further strengthen the stand of the HOA's in relation to the individual owner's interest, perceived or real. Ideally, panel buildings should be shifted from the "weak condominium ownership model" of today towards "housing cooperative" ownership models.

\section{Acknowledgements}

This paper was supported by the project "Development and support of multidisciplinary postdoctoral programs in major technical areas of national strategy of Research - Development Innovation" 4D-POSTDOC, contract no. POSDRU/89/1.5/S/52603, project co-funded by the European Social Fund through Sectorial Operational Program Human Resources Development 2007-2013.

\section{References}

[1] Egedy, T., A magyar lakótelepek helyzetének értékelése (The situation of high-rise housing estates in Hungary), Földrajzi Értesítő XLIX. (2000) 3-4. füzet, pp. 265-283. - In Hungarian

[2] I. Demeter, Seismic Retrofit of Precast RC Walls by Externally bonded CFRP composites, PhD Thesis, Uni. Politehnica din Timisoara, (2011)

[3] Demeter, I., Short history of large panel structures in Romania, Scientific Bulletin of the Politehnica University of Timisoara, Vol. 51(65), No. 1, 87-94. (2005)

[4] Information on epp.eurostat.ec.europa.eu/statistics_explained/index.php/Housing_statistics

[5] S. Brzev and T. Guevara-Perez, Precast Concrete Construction (www.world-housing.net)

[6] G. Petrescu, C. Stamatiade, E. Bungardean, Reabilitarea termica a blocurilor de locuinte, Program national realizat in colaborare cu autorităţile administraţiei publice locale, (Thermal rehabilitation of block buildings, National program carried out together with local authorities) www.mdrl.ro - In Romanian

[7] V. Voinescu, Asociatii de proprietari, puse la zid (Home owner associations put to the wall), Jurnalul de Dambovita, 18.07.2012 - In Romanian

[8] Information on www.adevarul.ro

[9] Information on www.locatar.ro/Forum

[10] Information on http://virtual.vtt.fi/virtual/respire/pictures.html

[11] FAPR - Owner Associations Federation from Romania (www.fapr.ro)

[12] Raportare stiintifica: Contract nr: 3002/2011 Strategii şi politici pentru reabilitarea termică a clădirilor în vederea reducerii consumului primar de energie şi reducerea emisiilor de gazelor cu efect de seră - InSPIRe, Uni. Politehnica din Timisoara, (2011) 